\title{
Evaluation of an elastic decellularized tendon-derived scaffold for the vascular tissue engineering application
}

Citation for published version (APA):

Ghazanfari, S., Alberti, K. A., Xu, Q., \& Khademhosseini, A. (2019). Evaluation of an elastic decellularized tendon-derived scaffold for the vascular tissue engineering application. Journal of Biomedical Materials Research Part A, 107(6), 1225-1234. https://doi.org/10.1002/jbm.a.36622

Document status and date:

Published: 01/06/2019

DOI:

10.1002/jbm.a.36622

Document Version:

Publisher's PDF, also known as Version of record

Document license:

Taverne

Please check the document version of this publication:

- A submitted manuscript is the version of the article upon submission and before peer-review. There can be important differences between the submitted version and the official published version of record.

People interested in the research are advised to contact the author for the final version of the publication, or visit the DOI to the publisher's website.

- The final author version and the galley proof are versions of the publication after peer review.

- The final published version features the final layout of the paper including the volume, issue and page numbers.

Link to publication

\footnotetext{
General rights rights.

- You may freely distribute the URL identifying the publication in the public portal. please follow below link for the End User Agreement:

www.umlib.nl/taverne-license

Take down policy

If you believe that this document breaches copyright please contact us at:

repository@maastrichtuniversity.nl

providing details and we will investigate your claim.
}

Copyright and moral rights for the publications made accessible in the public portal are retained by the authors and/or other copyright owners and it is a condition of accessing publications that users recognise and abide by the legal requirements associated with these

- Users may download and print one copy of any publication from the public portal for the purpose of private study or research.

- You may not further distribute the material or use it for any profit-making activity or commercial gain

If the publication is distributed under the terms of Article $25 \mathrm{fa}$ of the Dutch Copyright Act, indicated by the "Taverne" license above, 


\title{
Evaluation of an elastic decellularized tendon-derived scaffold for the vascular tissue engineering application
}

\author{
Samaneh Ghazanfari, ${ }^{1,2,3}$ Kyle A. Alberti, ${ }^{4}$ Qiaobing Xu, ${ }^{4}$ Ali Khademhosseini ${ }^{1,2,5,6,7}$ \\ ${ }^{1}$ Biomaterials Innovation Research Center, Division of Biomedical Engineering, Department of Medicine, Brigham and Women's \\ Hospital, Harvard Medical School, Boston, Massachusetts \\ ${ }^{2}$ Harvard-Massachusetts Institute of Technology, Division of Health Sciences and Technology, Massachusetts Institute of \\ Technology, Cambridge, Massachusetts \\ ${ }^{3}$ Aachen-Maastricht Institute for Biobased Materials, Faculty of Science and Engineering, Maastricht University, Geleen, The \\ Netherlands \\ ${ }^{4}$ Department of Biomedical Engineering, Tufts University, Boston, Massachusetts \\ ${ }^{5}$ Wyss Institute for Biologically Inspired Engineering, Harvard University, Boston, Massachusetts \\ ${ }^{6}$ Department of Bioindustrial Technologies, College of Animal Bioscience and Technology, Konkuk University, Hwayang-dong, \\ Gwangjin-gu, Seoul, Republic of Korea \\ ${ }^{7}$ Department of Bioengineering, Department of Radiology, Department of Chemical and Biomolecular Engineering, University of \\ California, Los Angeles, California
}

Received 9 August 2018; revised 26 December 2018; accepted 30 December 2018

Published online 18 February 2019 in Wiley Online Library (wileyonlinelibrary.com). DOI: 10.1002/jbm.a.36622

\begin{abstract}
Due to the limited success rate of currently available vascular replacements, tissue engineering has received tremendous attention in recent years. A main challenge in the field of regenerative medicine is creating a mechanically functional tissue with a well-organized extracellular matrix, particularly of collagen and elastin. In this study, the native collagen scaffold derived from decellularized tendon sections, as a scaffold having the potential to be used for vascular tissue engineering applications, was studied. We showed that the elasticity of the scaffolds was improved when crosslinked with the bovine elastin. The effect of different concentrations of elastin on mechanical properties of the collagen scaffolds was evaluated of which $15 \%$ elastin concentration was selected for further analysis based on the results. Addition of 15\% elastin to collagen scaffolds significantly decreased Young's modulus and the tensile stress at the maximum load and increased the
\end{abstract}

tensile strain at the maximum load of the constructs as compared to those of the collagen scaffolds or control samples. Moreover, tubular elastin modified collagen scaffolds showed significantly higher burst pressure compared to the control samples. Smooth muscle cells and endothelial cells cultured on the elastin modified collagen scaffolds showed high viability $(>80 \%)$ after 1,3 , and 7 days. Furthermore, the cells showed a high tendency to align with the collagen fibers within the scaffold and produced their own extracellular matrix over time. In conclusion, the results show that the decellularized tendon sections have a great potential to be used as scaffolds for vascular tissue engineering applications. (c) 2019 Wiley Periodicals, Inc. J Biomed Mater Res Part A: 107A: 1225-1234, 2019.

Key Words: collagen, elastin, biomimetic scaffolds, vascular tissue regeneration, biomechanical properties

How to cite this article: Ghazanfari S, Alberti KA, Xu Q, Khademhosseini A. 2019. Evaluation of an elastic decellularized tendonderived scaffold for the vascular tissue engineering application. J Biomed Mater Res Part A 2019:107A:1225-1234.

\section{INTRODUCTION}

Vascular diseases are a leading cause of death in the world. ${ }^{1}$ Many surgeries are performed every year in order to replace a diseased vessel with a vascular graft. Coronary, cerebral, and peripheral arteries are commonly diseased vessels. ${ }^{2}$ Synthetic grafts, such as polytetrafluoroethylene (PTFE), are often used as large diameter vascular replacements. ${ }^{3}$ However, they do not perform well when used for small diameter replacements $(<6 \mathrm{~mm})$ as they are prone to infection, thrombus formation, or intimal hyperplasia, which finally results in occlusion and failure of the grafts. ${ }^{3,4}$ Autologous vessels, such as saphenous veins, are currently used instead, but not all patients have a healthy vessel suitable for use. ${ }^{5}$

Tissue-engineered vascular grafts, having the ability to remodel and grow, are currently studied as promising alternatives for vascular graft replacements. ${ }^{3,5}$ Under physiological pulsatile blood pressure of $80-120 \mathrm{mmHg}$, the vessel wall is subjected to the circumferential stresses and strains of $100-150 \mathrm{kPa}$ and $10 \%-15 \%$, respectively. ${ }^{6}$ The main dilemma in vascular tissue engineering is that the engineered grafts are not mechanically robust enough to withstand in vivo hemodynamic forces and do not possess elastic 
(A)
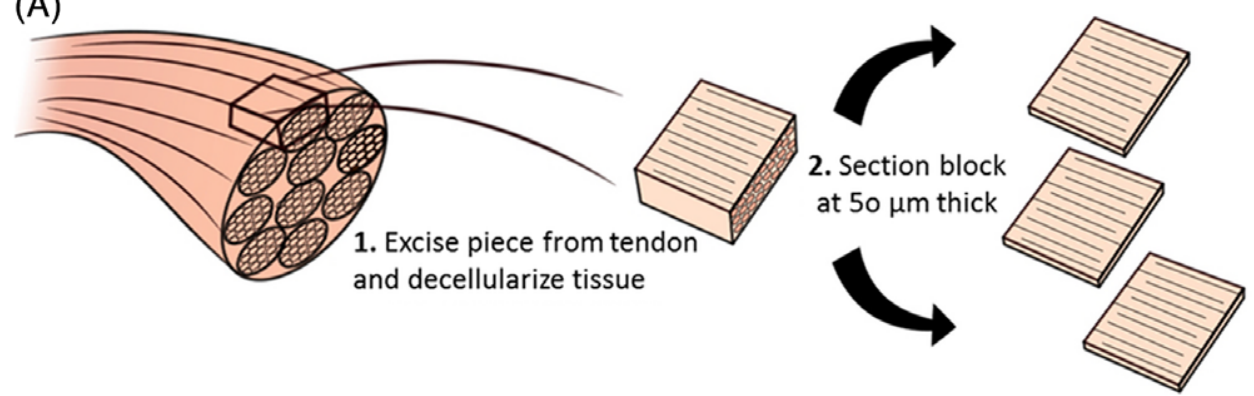

3. Roll pieces around
a rod

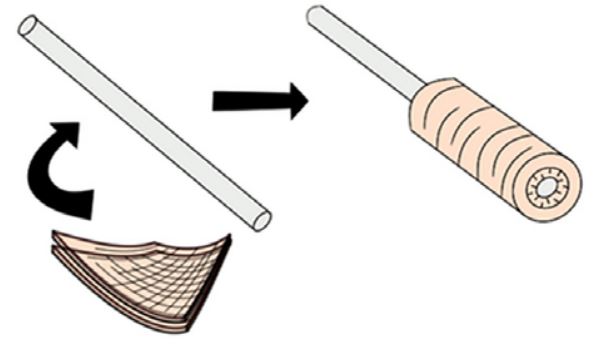

(B)

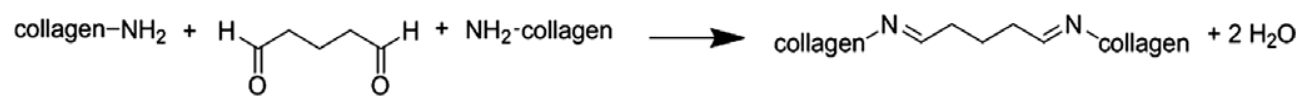

FIGURE 1. (A) Schematic drawing of scaffold fabrication. Decellularized tendon blocks (1) were sectioned into $50 \mu \mathrm{m}$ slices (2). To make sheets, three slices were stacked on top of each other. However, to make tubes, 10 slices were stacked with alternating fiber orientation and rolled around a Teflon rod (3). (B) Reaction scheme for the crosslinking of collagen with butyraldehyde. The crosslinking mechanism is based on imine formation between amino groups in collagen and aldehyde functions from glutaraldehyde.

properties. $^{7}$ The presence of a well-organized extracellular matrix (ECM), especially one containing collagen and elastin components, is shown to be essential in providing mechanical strength and compliance and maintaining long-term functionality.

Mechanical properties and structure of blood vessels vary depending on their anatomical location and function. ${ }^{8}$ For example, in terms of the mechanical stiffness, Young's modulus of 16.7 and $700 \mathrm{kPa}$ was reported for human coronary arteries and porcine carotid arteries, respectively. ${ }^{9}$ In general, collagen is the major reinforcing ECM component in the vessel wall, and its anisotropic structural arrangement results in mechanical strength of the wall. ${ }^{10}$ Elastin is another essential element of the ECM providing elasticity to the vascular wall. ${ }^{11}$ In tissue-engineered blood vessels, scaffolds have been used to provide initial mechanical properties to the growing tissue. Moreover, they have been used as a template for the cells to synthesize their ECM in a desired direction, preferably identical to their native counterparts. Since topological features provided by the scaffold direct the orientation of both the cells and the synthesized ECM, it is important to use a scaffold with appropriate alignment to produce constructs with initial native-like anisotropic structure. ${ }^{12-14}$

For vascular tissue engineering applications, the scaffold should be biodegradable, biocompatible, possess native-like anisotropic mechanical properties and structure and be producible in a tubular configuration. The structure and properties of a scaffold are influenced by the material and production procedure. Due to low antigenic and inflammatory properties of collagen, as a biodegradable natural polymer, it could represent a potential material for vascular tissue engineering. ${ }^{15-17}$ In order to create topological features on collagen scaffolds, methods such as electrospinning. ${ }^{18}$ and micropatterning ${ }^{19}$ can be applied. However, it is not possible to maintain the native triple helix structure and properties of the collagen through these fabrication techniques. We recently developed a technique to fabricate collagen scaffolds from decellularized tendon, which keeps the native structure of collagen fibers and allows us to produce tubular constructs. ${ }^{20,21}$

By applying our scaffold fabrication technique on tendonderived collagen, both flat and tubular constructs can be produced while the native triple helix structure of collagen fibers and the proteoglycan content is maintained. ${ }^{22,23}$ This means that the scaffold can provide both anisotropic mechanical strength and contact guidance cues due to its natural topographical features, besides providing a natural substrate for cells to interact with. It was shown in a previous study that anisotropic mechanical properties of the scaffold could be manipulated by either adding a crosslinking agent or changing the orientation of the stacked tendon slices. ${ }^{20}$ It should be also noted that depending on the structure of the native target vessel tissue, the alignment and number of stacked slices could be altered. Since elastin is not vastly present in tendon tissues and elasticity is an essential property of native vascular tissues, these collagen scaffolds need to be optimized in this regard by addition of an elastic component.

The aim of the current study was to evaluate the feasibility of using tendon-derived collagen scaffolds for vascular 
tissue engineering applications. First, the effect of different concentrations of elastin on the mechanical properties of the scaffolds was studied and the optimum concentration was chosen. Physical characteristics of collagen scaffolds were analyzed by measuring the swelling ratio and via scanning electron microscopy (SEM) measurements. Furthermore, the burst pressure was measured on tubular scaffolds. The viability and alignment of cells cultured on scaffold sheets were also analyzed. Lastly, the mechanical properties and the amount of hydroxyproline as a measure of collagen produced by the cells seeded on the scaffolds with time were evaluated.

\section{MATERIALS AND METHODS Scaffold fabrication}

Frozen bovine Achilles tendon was sliced into blocks of $\sim 20$ $\times 20 \times 2 \mathrm{~mm}$ using a cryomicrotome (CM1950, Leica Microsystems, Buffalo Grove, IL). The slices were placed into a decellularization solution $(1 \% \mathrm{w} / \mathrm{v}$ sodium dodecyl sulfate (SDS) (Sigma, St. Louis, MO), $1 \mathrm{mM}$ Tris-HCl, $0.1 \mathrm{mM}$ EDTA (Tris-EDTA pH 7.4, Sigma) in phosphate buffered saline (PBS)) shaking for $48 \mathrm{~h}$ at $4^{\circ} \mathrm{C}$. The solution was changed after $24 \mathrm{~h}$. In order to remove residual SDS, the blocks were then rinsed in deionized water $\left(\mathrm{diH}_{2} \mathrm{O}\right)$ for $24 \mathrm{~h}$. The blocks were sectioned at $50 \mu \mathrm{m}$ thick. As shown in Figure 1(A), individual sheets were produced by placing a section on a PTFE block, while tubular conduits were created by rolling individual $50 \mu \mathrm{m}$ sections around PTFE rods, $3.175 \mathrm{~mm}$ in diameter. An initial section was placed on the rod with fibers oriented parallel to the axis of the rod; subsequent sections were alternated by $90^{\circ}$ creating axial and circumferential orientations. The sections were allowed to dry on the rod, rehydrated and rinsed in three changes of $\mathrm{diH}_{2} \mathrm{O}$. In order to increase the extensibility of the scaffold, stacks of three individual sheets having the fibers aligned as well as the tubular scaffolds were soaked in the indicated concentration $(10 \%$, $15 \%$, and $20 \%$ ) of elastin from bovine neck ligament (Sigma) containing $0.1 \%$ of glutaraldehyde (GA) for crosslinking [Fig. 1(B)]. The soaked sheets and tubes were placed on ice for $3 \mathrm{~h}$ to let the elastin diffuse within the sheets prior to complete crosslinking. Crosslinked elastin samples without the presence of collagen scaffold were mechanically weak, and non-crosslinked collagen sheets were difficult to handle without any damage and thus excluded from further analysis. Samples without elastin were crosslinked by immersion in $0.1 \%$ of GA for $20 \mathrm{~min}$. All samples were then washed three times in $\mathrm{diH}_{2} \mathrm{O}$. A group of scaffolds was analyzed in terms of mechanical properties, swelling ratio and structure before seeding the cells. Three samples per group were included in each analysis.

\section{Cell culture}

Human smooth muscle cells (SMCs) and endothelial cells (ECs) were obtained from Lonza (Walkersville, MD), and were cultured in SMCs and ECs growth medium (Lonza), respectively, containing $10 \%$ fetal bovine serum. The scaffold sheets were seeded with either SMCs or ECs from passage 5 . The scaffolds were sterilized in $70 \%$ ethanol before cell seeding and then washed in PBS. Subsequently, the scaffolds were placed in tissue engineering medium (cell culture medium supplemented with L-ascorbic acid 2-phosphate [0.25 mg/mL, Sigma, USA]) for $24 \mathrm{~h}$ to enhance cell attachment. $^{24}$ Then, the scaffolds were placed in the PDMS rectangular wells to avoid the cells from attaching to the wells, and were seeded with cells with a density of 3 million per $\mathrm{cm}^{3}$. The tissue engineering medium was replaced twice per week. To analyze the cell viability and cell orientation, the samples were cultured for 1, 3, and 7 days. Moreover, to evaluate the mechanical properties and hydroxyproline amount, as a measure of collagen production, the constructs were cultured for 1,2 , and 3 weeks. The tubular constructs were also cultured for 3 weeks. All analyses were performed on 3 individual samples per group per time point.

\section{Mechanical characterization}

Uniaxial tensile testing of the samples was performed using a mechanical tester (Instron, Norwood, MA) at a strain rate of $1 \mathrm{~mm} / \mathrm{min}$ with a $10 \mathrm{~N}$ load cell. The dimension of the samples was measured with a digital caliper before each test. Tensile stress and strain at the maximum load and the elastic modulus calculated from the second linear region of the stress-strain curve were determined. The elastic modulus was calculated via linear regression of the slope of the curve.

\section{Scanning electron microscopy}

Samples were lyophilized and placed on aluminium pin mounts. All samples were sputter-coated with gold prior to imaging and imaged with XL20 (FEI Company). Collagen sheets and $15 \%$ elastin modified sheets were imaged.

\section{Swelling ratio}

The swelling behavior of collagen sheets and 15\% elastin modified sheets were determined in PBS at $37^{\circ} \mathrm{C}$ as previously described. ${ }^{25}$ In short, samples were lyophilized and their weights were measured. After $24 \mathrm{~h}$ incubation in PBS, the samples were removed from PBS and reweighted. The swelling ratio was calculated based on the following equation: (Wwet-Wdry)/Wdry $\times 100 \%$, in which Wdry is the weight of the sample after lyophilizing and Wwet is after removal of the sample from PBS.

\section{Burst pressure measurement}

Burst pressure was calculated from the tubular conduits using an in-house built device based on designs modified from Gray et al. ${ }^{26}$ A syringe pump (NE-1000, New Era Pump Systems Inc., Farmingdale, NY) was used to generate pressure, which was measured using a gage pressure transducer with a 0-100 Psi range (PX26-100GV, Omega, Stamford, CT) coupled to a voltage meter (DP25B-S, Omega) and the sample diameter was recorded using a Sony $\alpha 6000$ camera with a SEL30M35 30 mm F3.5 macro lens (Sony). Tubular samples were mounted to dispensing needles using epoxy. The epoxy was allowed to cure for $1 \mathrm{~h}$ and the samples rehydrated using $\mathrm{diH}_{2} \mathrm{O}$. The syringe pump was set to a flow rate of $1 \mathrm{~mL} / \mathrm{min}$ or $10 \mathrm{~mL} / \mathrm{min}$, the system cleared of air, and the exit flow shut off, increasing pressure in the system. 

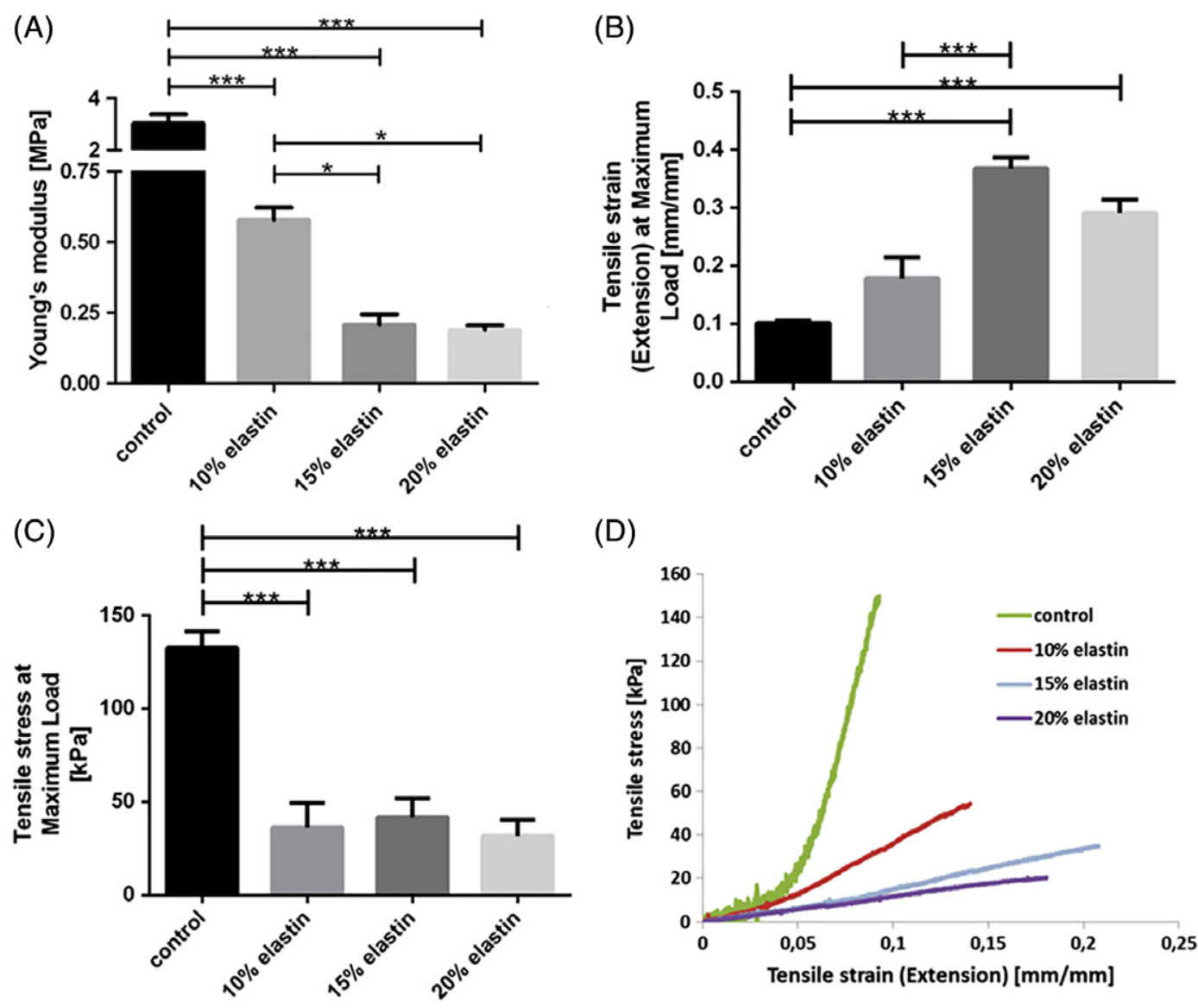

FIGURE 2. Young's modulus (A), tensile strain at the maximum load (B), tensile stress at the maximum load (C), and representative tensile stressstrain curves (D) of collagen sheets crosslinked with different elastin concentrations (0\% (control), 10\%, 15\%, and 20\%). Young's modulus was significantly lower and tensile strain at the maximum load was significantly higher in samples crosslinked with $15 \%$ elastin compared to the control and $10 \%$ elastin modified samples $(A, B)$. Moreover, the tensile stress was significantly lower in $15 \%$ elastin modified samples compared to the control group (C). Observed power for $\mathrm{A}, \mathrm{B}$, and $\mathrm{C}$ was $1 .(* p<0.05, * * p<0.01, * * * p<0.001)$.

The samples were tested until failure while being imaged. Frames of the initial and final diameter were extracted from video recordings of the tested tubes. The diameter was calculated using Image J (NIH, Bethesda, ML).

\section{Cell viability}

Cell viability was assessed using a Live/Dead viability assay kit (Invitrogen, USA) following instruction from the manufacturer at day 1,3 , and 7. Fluorescence images were taken using an inverted fluorescence microscope (Nikon TE 2000-U, Nikon instruments Inc., USA). Image J was used to count the live and dead cells. Cell viability was calculated by dividing the number of live cells by the total number of stained cells.

\section{Cell alignment}

Tissues were fixed using $4 \%$ formaldehyde after culturing. They were permeabilized for $30 \mathrm{~min}$ in $0.5 \%$ Triton-X in PBS, and were incubated with FITC-conjugated phalloidin (1:100, Sigma) for $30 \mathrm{~min}$ at room temperature. The images were taken using an inverted fluorescence microscope (Nikon TE 2000-U, Nikon instruments Inc., USA). To evaluate the local fiber orientation, an Image J plug-in called Orientation J was used. ${ }^{27}$

\section{Total collagen analysis}

To determine the amount of hydroxyproline, as a measure of collagen amount, a modified protocol developed by Huszar et al. was used. ${ }^{28}$ Samples were digested in papain solution (11 $\mathrm{mM}$ phosphate buffer, $\mathrm{pH}=6.5,5 \mathrm{mM}$ L-cysteine, $5 \mathrm{mM}$ EDTA, and 125-140 $\mu \mathrm{g}$ papain per $\mathrm{ml}$ ) for $16 \mathrm{~h}$. Standard curves were obtained from trans-4-hydroxyproline (Sigma). The collagen amount is shown as $\mu$ g per mg dry weight.

\section{Statistical analysis}

Mechanical characteristics, cell viability and collagen content data are presented as mean \pm standard error of mean. Oneway ANOVA, followed by Tukey's multiple comparison post hoc test, was used to determine the difference between different time points. Furthermore, to test the statistical differences between samples with/without elastin crosslinking or with/without cell seeding in time, two-way ANOVA was performed. GraphPad Prism software (GraphPad Software, Inc.) was used to perform statistical analysis. A $p$ value $<0.05$ was considered significant. Finally, observed power was calculated using SPSS (IBM Corp, NY). 


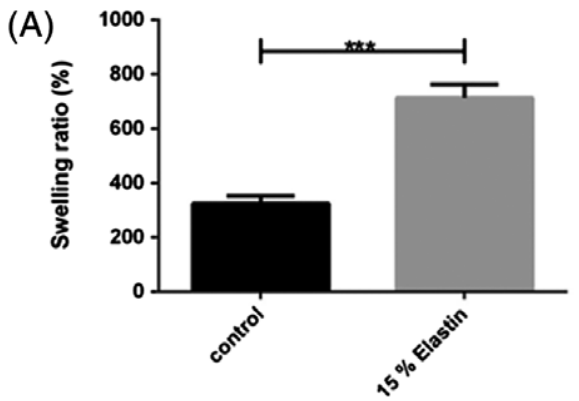

(B)

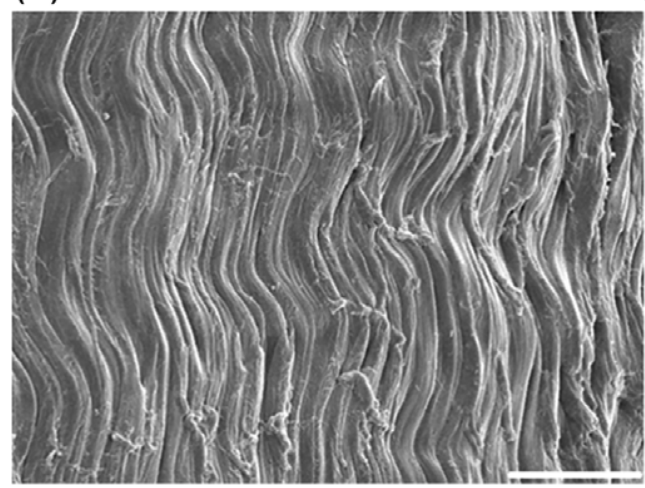

(C)

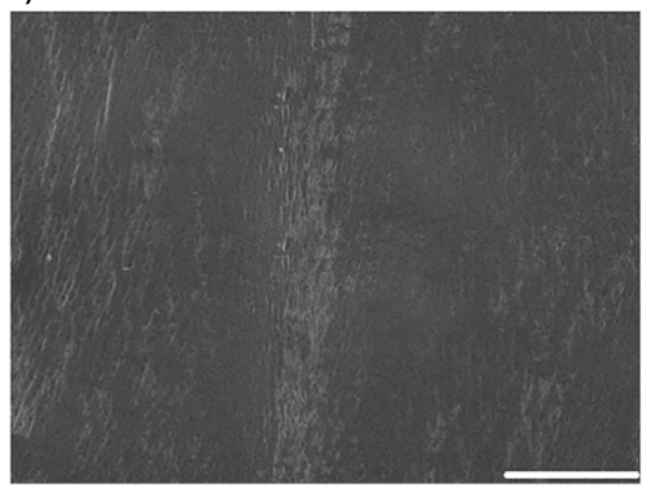

FIGURE 3. Swelling properties (A) and representative SEM images (B,C) of non-modified and $15 \%$ elastin modified collagen sheets. The swelling ratio was significantly elevated when collagen sheets were modified with $15 \%$ elastin with the observed power equal to 1 ( $A$ ). Further, SEM images revealed anisotropic alignment of collagen fibers $(B, C)$.

\section{RESULTS}

\section{Physical characterization}

Young's modulus, tensile strain at the maximum load and tensile stress at the maximum load were significantly influenced by crosslinking the collagen sheets with elastin (Fig. 2). Young's modulus of the control and $10 \%$ elastin modified collagen sheets were significantly higher than $15 \%$ and $20 \%$ elastin modified sheets. While, there was no significant difference between $15 \%$ and $20 \%$ elastin modified sheets [Fig. 2(A)]. Furthermore, tensile strain at the maximum load of $15 \%$ elastin modified sheets was significantly higher than the control and 10\% elastin modified samples. Again, there was no significant difference between $15 \%$ and $20 \%$ elastin modified sheets [Fig. 2(B)]. On the other hand, there was no significant difference between tensile stress at the maximum load of $10 \%, 15 \%$, and $20 \%$ elastin modified sheets, while they were all significantly lower than the control [Fig. 2(C)]. Representative tensile stress versus strain curves showed that by crosslinking the sheets with $15 \%$ elastin, the extensibility of the scaffold was tremendously increased [Fig. 2(D)]. Based on the mechanical properties data, collagen sheets crosslinked with $15 \%$ elastin had been selected for further investigations.

The swelling ratio of $15 \%$ elastin modified sheets was significantly higher as compared to the control [Fig. 3(A)]. The SEM images demonstrated that the natural wavy structure of collagen fibers was preserved during the scaffold preparation [Fig. 3(B)] and elastin solution homogeneously diffused into the collagen fibers [Fig. 3(C)]. The burst pressure in elastin modified collagen tubes was significantly higher as compared to non-modified collagen tubes when both $1 \mathrm{~mL} / \mathrm{min}$ and $10 \mathrm{~mL} / \mathrm{min}$ flow rates were applied [Fig. 4(A,B)]. There was no significant difference between SMCs seeded collagen tubes and elastin modified or nonmodified collagen tubes [Fig. 4(A)]. The representative image of elastin modified collagen tubes clearly shows the tremendous inflation of the tubes after a defined flow rate was applied [Fig. 4(C)]. Finally, it should be mentioned that the inner and outer diameters of the SMCs seeded collagen tubes after 3 weeks of culture were not significantly different than those of the control group (data not shown).

\section{Cell-material interaction}

Live/Dead viability assay revealed that both spindle-shaped SMCs [Fig. 5(A)] and cobblestone-shaped ECs [Fig. 5(B)] could attach and grow on the collagen sheets, suggesting their biocompatibility. Both cell types cultured on the collagen sheets for 1,3 , and 7 days showed the cell viability of over $80 \%$ [Fig. $5(\mathrm{C})$ ]. The cell viability of both SMCs and ECs was significantly increased after 7 days as compared to the first day. Cell orientation distribution revealed that both SMCs [Fig. 6(A)] and ECs [Fig. 6(B)] stayed aligned with the collagen fibers of the sheets on which they are cultured after 1, 3, and 7 days (Fig. 6).

\section{Mechanical properties and collagen production in vitro}

There was no significant difference between Young's modulus of SMCs seeded and cell-free control collagen sheets as well as SMCs seeded and cell-free elastin modified collagen 


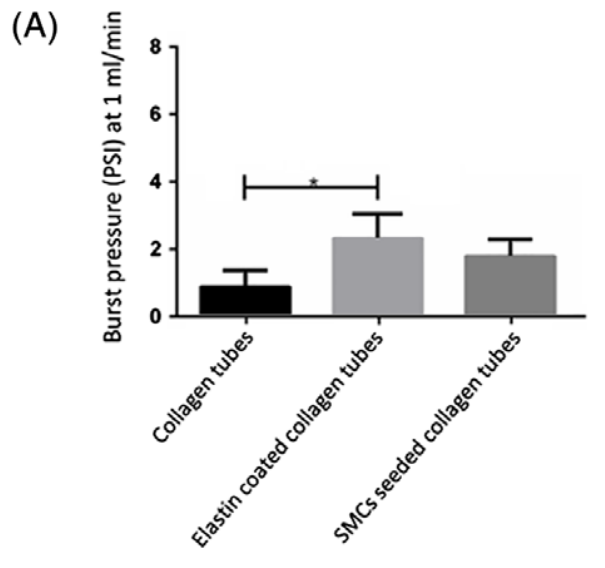

(B)
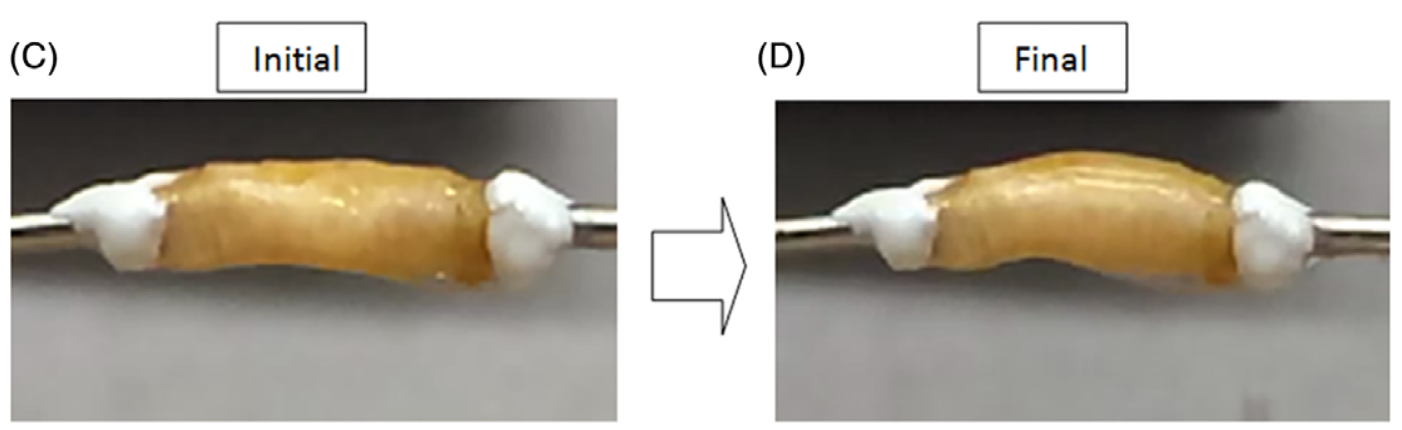

FIGURE 4. The burst pressure of non-modified, modified and SMCs seeded collagen tubes at a rate of $1 \mathrm{~mL} / \mathrm{min}(\mathrm{A})$, non-modified and elastinmodified collagen tubes at a rate of $10 \mathrm{~mL} / \mathrm{min}(\mathrm{B})$, and representative images of elastin modified tubes before and after the burst pressure measurement (C). Elastin modified tubes had significantly higher burst pressure at both rates compared to non-modified collagen tubes. Further, the burst pressure of SMCs seeded collagen tubes was not significantly different from unseeded and elastin modified collagen tubes. Observed power for $\mathrm{A}$ was 0.63 and for $\mathrm{B}$ was 0.93 .

sheets with time. However, Young's modulus of nonmodified collagen sheets was significantly higher than both seeded and cell-free elastin modified sheets at all time points [Fig. 7(A)]. As shown in Figure 7(B), tensile strain at the maximum load of both seeded and cell-free collagen sheets was significantly lower than seeded and cell-free elastin modified sheets after 1 week. However, this value was significantly lower only in SMCs seeded collagen sheets as compared to both seeded and cell-free elastin modified sheets at week 2. Furthermore, there was no significant difference between all four groups after 3 weeks. The collagen amount was significantly higher in SMCs seeded collagen sheets as compared to cell-free collagen sheets after 2 and 3 weeks of culture [Fig. $7(\mathrm{C})]$.

\section{DISCUSSION}

The aim of this study was to evaluate the feasibility of using decellularized tendon-derived scaffolds as a natural substrate for vascular tissue engineering applications. It has been known that a functional vascular graft should have tensile strength to provide mechanical stability, elasticity to provide rebound and avoid aneurysm development, and a confluent endothelial layer to avoid thrombogenic and immunogenic complications. Since the mechanical properties of tissue engineered vascular grafts are determined by the properties of the scaffold before the developing tissue produces its own matrix, it is important that the scaffold can provide appropriate physical and mechanical properties at the early stages of tissue development. Collagen has been shown to be an appropriate material in many biomedical applications; ${ }^{29,30}$ for instance, decellularized tendon-derived scaffold was shown to be a suitable substrate for nerve regeneration in both in vitro and in vivo studies. ${ }^{31,32}$ In this study, we evaluated the feasibility of using decellularized tendon-derived scaffolds for vascular regeneration applications. Since elasticity is essential for these applications, ${ }^{33}$ the scaffolds were crosslinked with the bovine elastin to add an elastic component to the constructs.

It was shown previously that the architecture, mechanical properties and thickness of the vessel wall vary with respect to their anatomical location and age. These characteristics are defined by the physical stresses applied to the vessel wall by pressure and blood flow. ${ }^{34-36}$ Due to anisotropic mechanical properties and fibrous arrangement of the decellularized tendon-derived scaffold, we can create constructs with different thicknesses and alignments resembling those of the target vessel walls. Desired anisotropic mechanical properties can be reached by stacking sections in different directions and crosslinking the sheets with other natural materials such as elastin. In this study, we showed that by adding the bovine elastin to the scaffolds, the extensibility 
(A)

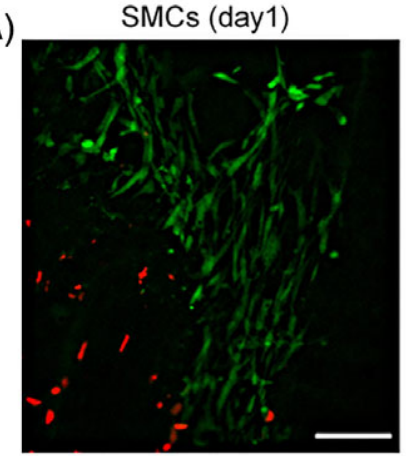

(B)

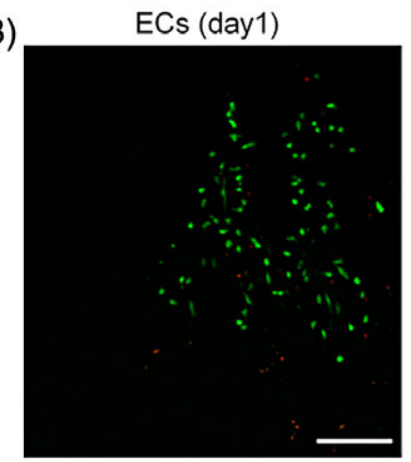

(C)

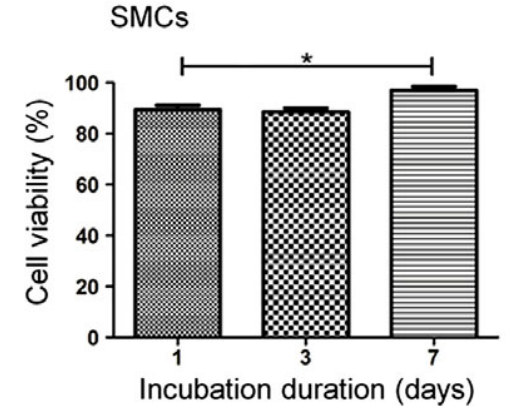

SMCs (day 3 )

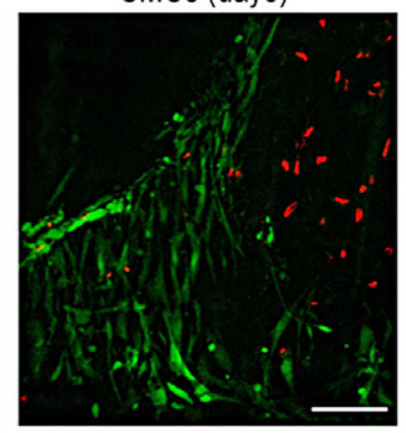

ECs (day3)

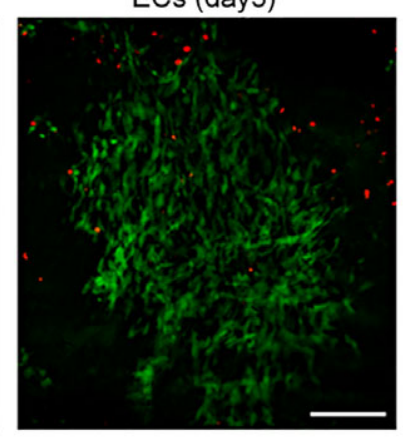

SMCs (day7)

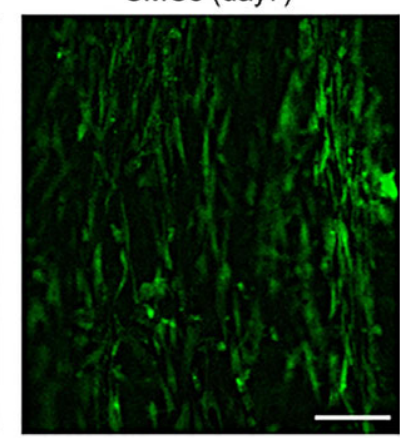

ECs (day7)

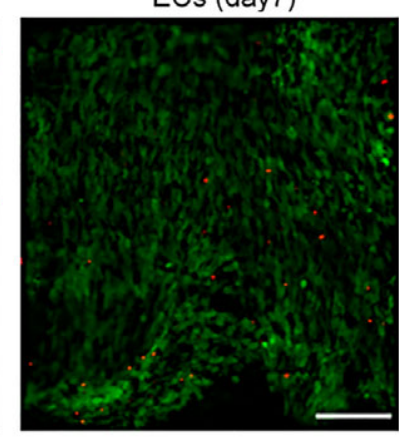

ECs

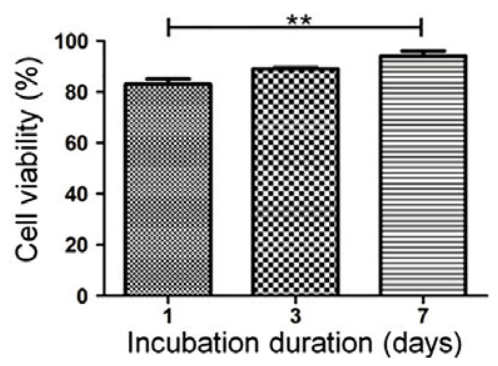

FIGURE 5. Representative images of live/dead assay of SMCs and ECs seeded on aligned collagen sheets at day 1 , day 3 , and day 7 of culture. Both SMCs (A) and ECs (B) seeded sheets became more confluent with time. Live cells are shown in green and dead cells in red. Scale bars represent $100 \mu \mathrm{m}(\mathrm{C})$. Cell viability for both SMCs and ECs increased significantly after 7 days (observed power for SMCs was 0.94 and for ECs was 0.99 ).

and Young's modulus of the scaffolds were significantly changed. We also showed in a previous study that the addition of glutaraldehyde improved the strength of the scaffolds significantly. ${ }^{37}$ Moreover, reduction of the scaffold modulus by addition of elastin was also shown in previous studies. ${ }^{9,38}$ However, it is not clear yet what mechanisms are involved in the reduction of the modulus, and should be explored in the future studies. Therefore, depending on the target vessel, constructs with different structures and mechanical properties can be created.

Conclusions from the mechanical properties and burst pressure measurements should be drawn carefully due to the limitations of the study. First, it should be mentioned that the thickness of the samples was measured using a digital caliper. This might result in undermeasurement of the dimensions as the samples can be squeezed during the measurements, which potentially can affect the mechanical properties results. Next, it is also important to evaluate the viscoelastic behavior of the constructs by stress-relaxation and by cyclic loading hysteresis analysis in the future studies.

Moreover, the infusion rate of 1 and $10 \mathrm{~mL} / \mathrm{min}$ were selected for burst pressure measurements based on a range obtained from previous studies. ${ }^{39-44}$ However, in another study, a higher infusion rate up to $100 \mathrm{~mL} / \mathrm{min}$ was applied. ${ }^{43}$ In this case, the leakage through the weak parts of the graft was avoided by application of a non-porous inner lining sleeve, which might finally lead to overestimation of the graft burst pressure. ${ }^{43}$ We also observed that sweating of the constructs was higher on collagen scaffolds which had bigger pores compared to the elastin-modified group as shown in the SEM images. This could be one of the reasons behind a faster burst and thus lower burst pressure in collagen tubes compared to the elastin-modified ones. Finally, in many studies, the infusion rate is not specified. ${ }^{45-49}$

There are no precise guidelines regarding the burst pressure measurements, which has led to a considerable 
(A)
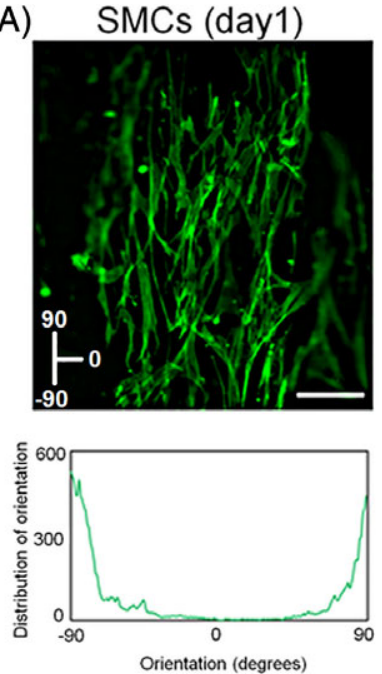

(B)
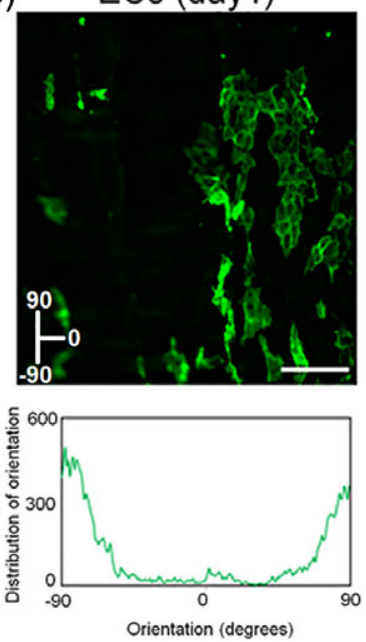
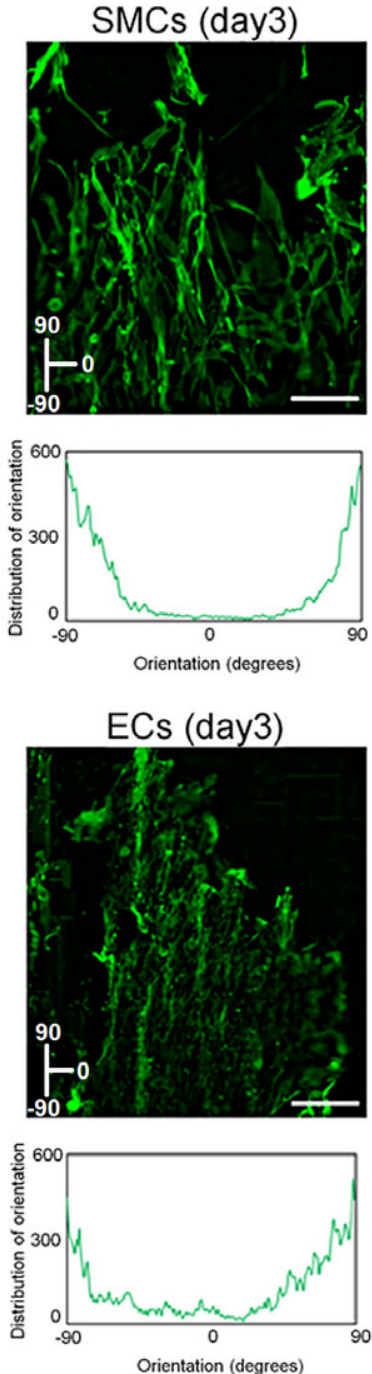
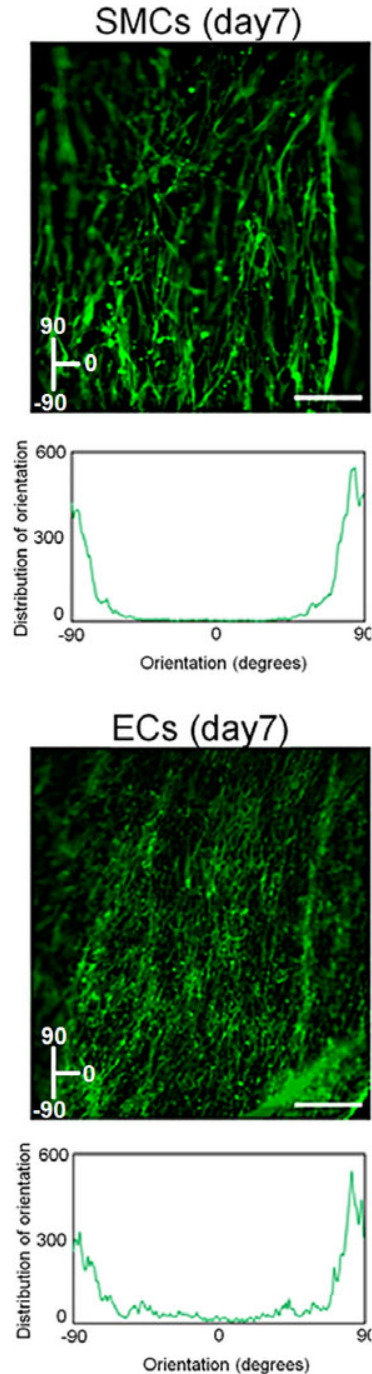

FIGURE 6. Representative F-actin stained SMCs (A) and ECs (B) seeded on collagen sheets and their corresponding orientation distribution. Both SMCs and ECs had an increase in confluency and stayed aligned with the sheets collagen fibers with time. Scale bars represent $100 \mu \mathrm{m}$.

variation of methods and parameters used in previous studies. ${ }^{43}$ Moreover, interaction of blood with the vessel wall is different than that of water as blood leaves a thin layer of clot on the luminal side of the grafts which ultimately seals the pores. Therefore, it is challenging to design a set-up which exactly mimics the parameters that are applied in an in vivo environment.

Another important issue when using a potential scaffold for a particular application is to look into the in vitro biocompatibility of the material. Parameters such as viability, proliferation, and attachment of cells are important in this regard. In this study, both SMCs and ECs showed a high rate of viability when cultured on collagen sheets. The cells formed almost a confluent layer after 7 days and aligned with the collagen fibers in the scaffold. Formation of a confluent layer of cells is important, especially when it comes to the functionality of the ECs as they are meant to avoid development of thrombogenic and immunogenic complications. ${ }^{34}$ Moreover, it is essential to guide the alignment of the
SMCs and consequently the ECM they produce to provide tissue engineered constructs with desired burst strength, compliance, and stability, preferably similar to their native counterparts. $^{34-36}$ The results showed that the scaffold is capable of guiding the orientation of the SMCs and that the ECs can form a confluent layer on the sheets. Another limitation of this study was that biological activity of the SMCs and the ECs and the maintenance of their phenotype over time were not evaluated and thus should be addressed in the future studies.

In conclusion, this study shows that the mechanical properties of decellularized tendon scaffolds can be tuned in order to be used for vascular tissue engineering applications. The extensibility of the scaffolds can be tuned by crosslinking with the bovine elastin. By addition of the elastin component, the burst pressure was also significantly increased. Both SMCs and ECs showed a high rate of viability, and formed a confluent layer after a week. Moreover, the SMCs could grow and align along the fibers in the tendon 
(A)

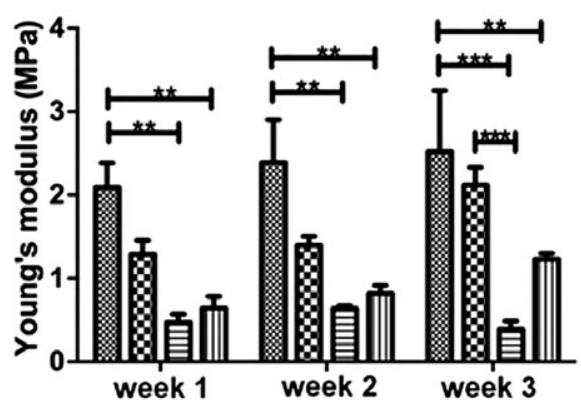

(B)

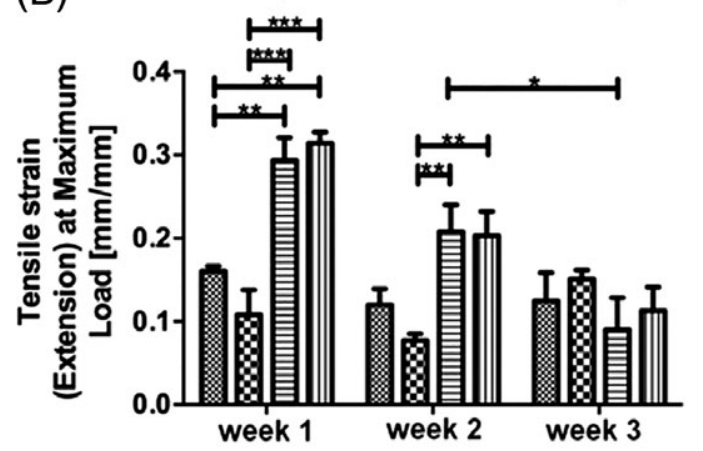

(C)

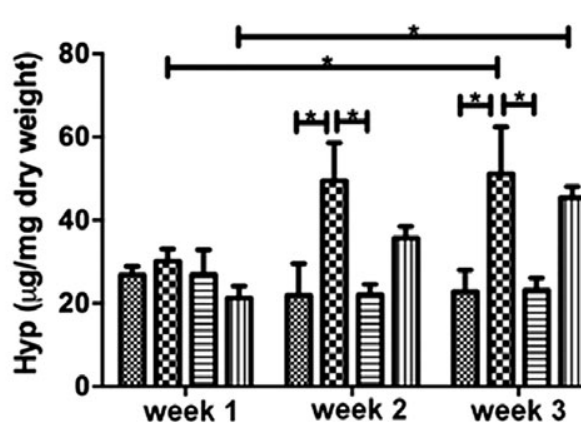

Collagen sheets

$\mathbb{B}$ SMCs seeded collagen sheets

Elastin-modified collagen sheets

SMCs seeded elastin-modified

collagen sheets
Collagen sheets

$\mathbb{W}$ SMCs seeded collagen sheets

目 Elastin-modified collagen sheets

IIII

SMCs seeded elastin-modified

collagen sheets

FIGURE 7. Young's modulus (A), tensile strain at the maximum load (B), and the collagen amount (C) of nonmodified, elastin modified, SMCs seeded and unseeded collagen sheets with time (1, 2, and 3 weeks). Young's modulus of both seeded and unseeded elastin modified scaffolds was lower compared to Young's modulus of unseeded collagen sheets at week 1, 2, and 3 and SMCs seeded collagen sheets at week 3 (observed power for the corrected model was 1) (A). Tensile strain at the maximum load of collagen sheets was significantly lower than that of elastin modified sheets after 1 week. However, this value was significantly lower only in SMCs seeded sheets as compared to elastin modified sheets after 2 weeks (observed power for the corrected model was 0.85 ) (B). The collagen amount in SMCs seeded collagen sheets was significantly higher compared to unseeded samples (observed power for the corrected model was 0.56) (C).

substrate. The cells could also produce their own ECM as an increase in the amount of collagen was revealed after 2 and 3 weeks. This scaffold might be of interest for in situ vascular tissue engineering applications where a cell-free scaffold can be fabricated with the desired fiber arrangement, thickness and mechanical properties before implantation. Future in vivo studies are needed to investigate the long-term functionality of these scaffolds.

\section{ACKNOWLEDGMENTS}

The authors would like to thank Nasim Annabi for providing the bovine elastin and Katrien Bernaerts for kindly preparing Figure 1(B).

\section{REFERENCES}

1. Arias $E$, Anderson RN, Kung HC, Murphy SL, Kochanek KD. Deaths: Final data for 2001. Natl Vital Stat Rep 2003;52:1-115.

2. Mathers $C D$, Loncar D. Projections of global mortality and burden of disease from 2002 to 2030. PLoS Med 2006;3:e442.

3. Dahl SL, Kypson AP, Lawson JH, Blum JL, Strader JT, Li Y, Manson RJ, Tente WE, DiBernardo L, Hensley MT, Carter R, Williams TP, Prichard HL, Dey MS, Begelman KG, Niklason LE. Readily available tissue-engineered vascular grafts. Sci Transl Med 2011;3:68ra9.

4. Schild AF, Perez E, Gillaspie E, Seaver C, Livingstone J, Thibonnier A. Arteriovenous fistulae vs. arteriovenous grafts: $A$ retrospective review of 1,700 consecutive vascular access cases. J Vasc Access 2008;9: 231-235.

5. Isenberg BC, Williams C, Tranquillo RT. Small-diameter artificial arteries engineered in vitro. Circ Res 2006;98:25-35.

6. Humphrey JD. Vascular adaptation and mechanical homeostasis at tissue, cellular, and sub-cellular levels. Cell Biochem Biophys 2008; 50:53-78. 
7. Salacinski HJ, Goldner S, Giudiceandrea A, Hamilton G, Seifalian AM, Edwards A, Carson RJ. The mechanical behavior of vascular grafts: $A$ review. J Biomater Appl 2001;15:241-278.

8. Fung YC. Biomechanics: Mechanical Properties of Living Tissues. New York: Springer Verlag; 1981

9. Ryan AJ, O'Brien FJ. Insoluble elastin reduces collagen scaffold stiffness, improves viscoelastic properties, and induces a contractile phenotype in smooth muscle cells. Biomaterials 2015;73:296-307.

10. Fratzl P. Collagen: Structure and Mechanics. New York: Springer; 2008.

11. Patel A, Fine B, Sandig M, Mequanint K. Elastin biosynthesis: The missing link in tissue-engineered blood vessels. Cardiovasc Res $2006 ; 71: 40-49$.

12. Ghazanfari S, Khademhosseini A, Smit TH. Mechanisms of lamellar collagen formation in connective tissues. Biomaterials 2016;97:74-84.

13. Ghazanfari S, Driessen-Mol A, Hoerstrup SP, Baaijens FPT, Bouten CVC. Collagen matrix remodeling in stented pulmonary arteries after transapical heart valve replacement. Cells Tissues Organs 2016;201:159-169.

14. Ghazanfari S, Driessen-Mol A, Sanders B, Dijkman PE, Hoerstrup SP, Baaijens FPT, Bouten CVC. In vivo collagen remodeling in the vascular wall of decellularized stented tissue-engineered heart valves. Tissue Eng Part A 2015;21(15-16):2206-2215.

15. Goissis G, Marcantonio EJ, Marcantonio RA, Lia RC, Cancian DC, de Carvalho WM. Biocompatibility studies of anionic collagen membranes with different degree of glutaraldehyde cross-linking. Biomaterials 1999;20:27-34.

16. Nicolas FL, Gagnieu CH. Denatured thiolated collagen II crosslinking by oxidation. Biomaterials 1997;18:815-821.

17. Alberti KA, Xu Q. Biocompatibility and degradation of tendonderived scaffolds. Regen Biomater 2016;3:1-11.

18. Schiffmana JD, Schauera CL. A review: Electrospinning of biopolymer nanofibers and their applications. Polym Rev 2008;48:317-352.

19. Théry M. Micropatterning as a tool to decipher cell morphogenesis and functions. J Cell Sci 2010;123:4201-4213.

20. Alberti KA, Xu Q. Slicing, stacking and rolling: Fabrication of nanostructured collagen constructs from tendon sections. Adv Healthc Mater 2013;2:817-821.

21. Dai $X$, Schalek $R, X u$ Q. Staining and etching: A simple method to fabricate inorganic nanostructures from tissue slices. Adv Mater 2012;24:370-374

22. Ning LJ, Zhang Y, Chen XH, Luo JC, Li XQ, Yang ZM, Qin TW. Preparation and characterization of decellularized tendon slices for tendon tissue engineering. J Biomed Mater Res A 2012;100:1448-1456.

23. Cartmell JS, Dunn MG. Development of cell-seeded patellar tendon allografts for anterior cruciate ligament reconstruction. Tissue Eng 2004;10:1065-1075.

24. Ghazanfari S, Driessen-Mol A, Strijkers GJ, Baaijens FPT, Bouten CVC. The evolution of collagen fiber orientation in engineered cardiovascular tissues visualized by diffusion tensor imaging. PLoS One 2015;10:e0127847.

25. Annabi N, Mithieux SM, Zorlutuna P, Camci-Unal G, Weiss AS, Khademhosseini A. Engineered cell-laden human protein-based elastomer. Biomaterials 2013;34:5496-5505.

26. Gray C, Oliva T, Christakis A, Rolle M, Billiar K. Design of a versatile, inexpensive vessel burst pressure measurement device. In: 2009 I.E. 35th Annual Northeast Bioengineering Conference, 2009;pp. 1-2.

27. Ruiz-Zapata AM, Kerkhof MH, Ghazanfari S, Zandieh-Doulabi B, Stoop R, Smit TH, Helder MN. Vaginal fibroblastic cells from women with pelvic organ prolapse produce matrices with increased stiffness and collagen content. Sci Rep 2016;6:22971.

28. Huszar G, Maiocco J, Naftolin F. Monitoring of collagen and collagen fragments in chromatography of protein mixtures. Anal Biochem 1980;105:424-429.

29. Ramshaw JM, Peng YY, Glattauer V, Werkmeister J. Collagens as biomaterials. J Mater Sci Mater Med 2009;20:S3-S8.

30. Lee $\mathrm{CH}$, Singla A, Lee Y. Biomedical applications of collagen. Int J Pharm 2001;221:1-22.
31. Alberti KA, Hopkins AM, Tang-Schomer MD, Kaplan DL, Xu Q. The behavior of neuronal cells on tendon-derived collagen sheets as potential substrates for nerve regeneration. Biomaterials 2014;35: 3551-3557.

32. Alberti $\mathrm{KA}$, Neufeld $\mathrm{Cl}$, Wang $\mathrm{J}, \mathrm{Xu} \mathrm{Q}$. In vivo peripheral nerve repair using tendon-derived nerve guidance conduits. ACS Biomater Sci Eng 2016;2:937-945.

33. Coenen AMJ, Bernaerts KV, Harings JAW, Jockenhoevel S, Ghazanfari S. Elastic materials for tissue engineering applications: natural, synthetic, and hybrid polymers. Acta Biomater 2018;79: 60-82.

34. Glagov S, Vito R, Giddenst DP, Zarins CK. Micro-architecture and composition of artery walls: Relationship to location, diameter and the distribution of mechanical stress. J Hypertens 1992;10:S101-S104.

35. Fata B, Carruthers CA, Gibson G, Watkins SC, Gottlieb D, Mayer JE, Sacks MS. Regional structural and biomechanical alterations of the ovine main pulmonary artery during postnatal growth. J Biomech Eng 2013;135:021022.

36. Ghazanfari S, Driessen-Mol A, Strijkers GJ, Kanters FMW, Baaijens FPT, Bouten CVC. A comparative analysis of the collagen architecture in the carotid artery: Second harmonic generation versus diffusion tensor imaging. Biochem Biophys Res Commun 2012; 426:54-58.

37. Alberti KA, Sun J, Illeperuma WR, Suo Z, Xu Q. Laminar tendon composites with enhanced mechanical properties. J Mater Sci 2015;50:2616-2625.

38. Daamen WF, van Moerkerk HT, Hafmans T, Buttafoco L, Poot AA, Veerkamp $\mathrm{JH}$, van Kuppevelt $\mathrm{TH}$. Preparation and evaluation of molecularly-defined collagen-elastin-glycosaminoglycan scaffolds for tissue engineering. Biomaterials 2003;24:4001-4009.

39. Wallace DG, Cruise GM, Rhee WM, Schroeder JA, Prior JJ, Ju J, Maroney M, Duronio J, Ngo MH, Estridge T, Coker GC. A tissue sealant based on reactive multifunctional polyethylene glycol. J Biomed Mater Res 2001;58:545-555

40. Klein SL, Chen H, Israel-Graff J. A comparison by burst testing of three types of vascular anastomosis. Microsurgery 1998;18:29-32.

41. Thierry B, Merhi Y, Silver J, Tabrizian M. Biodegradable membranecovered stent from chitosan-based polymers. J Biomed Mater Res A 2005;75:556-566.

42. Tamura N, Nakamura T, Terai H, Iwakura A, Nomura S, Shimizu Y. Komeda M. A new acellular vascular prosthesis as a scaffold for host tissue regeneration. Int J Artif Organs 2003;26:783-792.

43. Sarkar S, Hillery C, Seifalian A, Hamilton G. Critical parameter of burst pressure measurement in development of bypass grafts is highly dependent on methodology used. J Vasc Surg 2006;44: 846-852.

44. Krane C, Pinnell M, Gardner C, Thompson M, Coleman J, Wilkens R. Mechanical test methods for assessing porcine carotid and uterine artery burst pressure following ex vivo ultrasonic ligature seal and transection. J Test Eval 2011;39:514-521.

45. McFetridge PS, Daniel JW, Bodamyali T, Horrocks M, Chaudhuri JB. Preparation of porcine carotid arteries for vascular tissue engineering applications. J Biomed Mater Res A 2004;70:224-234.

46. Lamm P, Juchem G, Milz S, Schuffenhauer M, Reichart B. Autologous endothelialized vein allograft: $A$ solution in the search for small-caliber grafts in coronary artery bypass graft operations. Circulation 2001;104:I108-I114.

47. Roeder R, Wolfe J, Lianakis N, Hinson T, Geddes LA. Burst pressure of canine carotid arteries. Australas Phys Eng Sci Med 2000;23: 66-67.

48. Birch JF, Mandley DJ, Williams SL, Worrall DR, Trotter PJ, Wilkinson F, Bell PR. Methylene blue based protein solder for vascular anastomoses: An in vitro burst pressure study. Lasers Surg Med 2000;26:323-329.

49. Hoerstrup SP, Zund G, Sodian R, Schnell AM, Grunenfelder J, Turina MI. Tissue engineering of small caliber vascular grafts. Eur $J$ Cardiothorac Surg 2001;20:164-169. 